\title{
THE SIMULATION OF AN INFANTRY ATTACK USING GEOGRAPHICAL INFORMATION SYSTEMS
}

\author{
A. Pincevičius, R. Baušys*, P. Jankauskas \\ The General Jonas Žemaitis Military Academy of Lithuania, Šilo 5A, LT-10322 Vilnius. E-mail: pincev@takas.lt \\ *Vilnius Gediminas Technical University, Sauletekio al.11, LT-10223 Vilnius. E-mail: romas@fm.vtu.lt \\ Received 2012 2005, accepted 07092006
}
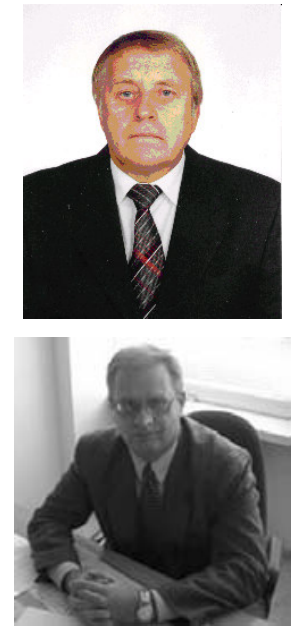

Albertas PINCEVIČIUS, Assoc Prof Dr

Date and place of birth: 1944 in Šeduva, Lithuania

Education: 1970 - Faculty of Physics of Vilnius University.

Affiliations and functions: 1980 - Doctor.

Research interests: Mathematical Modelling Operation: Modelling of Examinations of Semiconductor Materials,

Semiconductor Frames, Problems of Optimisation of Military Operations.

Teaching: Mathematics.

Publications: Author of more than 30 scientific articles; co-author of manual and two textbooks.

Present position: Associate Professor in Department of Applied Sciences at General Jonas Žemaitis Military Academy of Lithuania.

\section{Romualdas BAUŠYS, Prof Dr Habil}

Date and place of birth: 1958 in Vilnius, Lithuania.

Education: 1982 - Vilnius Civil Engineering Institute; 1989 - Scientific Degree of Doctor, 2000 - Habil. Doctor, 2001 Professor.

Publications: Author of more than 60 scientific articles.

Present position: Head of Graphical Systems Department at Vilnius Gediminas Technical University.

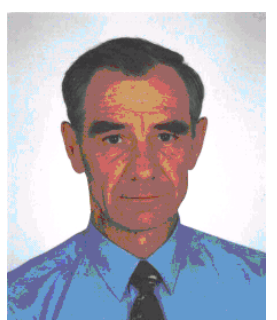

Pranas JANKAUSKAS, Dr

Date and place of birth: 1945 in Ančènai, Molètai District, Lithuania.

Education: 1976 - Engineering Academy of Moscow; 1981 - Adjuncture of Engineering Academy of Moscow.

Affiliations and functions: 1982 - Scientific Degree of Doctor.

Publications: Author of more than 70 scientific articles.

Inventions: 37 inventions.

Awards: 1994 - Third Degree Order of the Gediminas.

Present position: Deputy Chef of General Jonas Žemaitis Lithuanian Military Academy.

Abstract. An infantry attack over a specific terrain is modeled. A stochastic method described in our previous study is used. In this model, the position of each soldier during the attack is approximately defined by a square $[10 \mathrm{x} 10 \mathrm{~m}]$ on the battlefield. Making use of the possibilities inherent in a three-dimensional digital map, a visibility matrix is made up, i. e. the indication whether the enemy sees the soldier in a specific case is given.

Key words: modeling, military operations, stochastic models, geographical information systems.

\section{Introduction}

Mostly local wars break out nowadays and the number of military personnel participating in separate battles usually does not exceed a hundred. A platoonstrong (up to 30 soldiers) ambush is set, and about 100 of military personnel are sent for its liquidation. The actions of each soldier acquire great significance; besides, combat actions are affected by many random factors, the description of which by using analytical expressions is often practically impossible. It is not only manpower strength and armaments but also utilization of intelligence data, command and control, material support, exploitation of terrain relief features, meteorological conditions, etc. that influence military actions. The totality of these physical and informational factors, the interaction and effects of which are not completely understood, determine the outcome of a battle $[1,10]$. The objectives of military training at training areas are generally not concerned with grounding certain tactical elements or verifying statements. Besides, "military operations" in the training ground considerably differ from real battle. To 
confirm the fighting rules that determine the course of a battle, statistical data are necessary, because in each specific case a lot of random factors that distort the final result are at play. Only multiple recursive experiments make it possible to single out and exclude insignificant factors. The collection of such statistical data while conducting training at a training area is most often physically impossible. Besides, it would be very costly. Grounded quantitative recommendations for making an appropriate choice are in short supply. Yet it is possible to find grounded answers for many questions by using methods of mathematical modeling. In this case, a stochastic description method should be applied. For that purpose, statistical models and the Monte-Carlo model are used. Such methods help answer the questions "what must be done in order to reach a certain situation" and "what must be done in order to avoid a certain situation". Virtual reality thus becomes a key tool [10, 3]. It is definitely important in training a new generation of officers who will have to fight against international terrorism. The essential tool in creating virtual reality for training cadets is Geographical Information Systems (GIS). GIS make it possible effectively to process, analyze, and visualize information pertaining to the terrain [1]. The employment of GIS also allows costs allotted for training to be effectively controlled and decreased and training shortcomings to be eliminated [2, $8]$.

\section{Stochastic models of combat actions}

These essential battlefield actions of military personnel are modeled [7]:

- movement towards the adversary,

- observation and detection of the adversary,

- firing at and elimination of the adversary.

Analogous actions of the adversary are modeled, i. e. detection of the attackers and actions to eliminate them. When using a stochastic method, the separate actions of a soldier are described by random functions.

$\eta_{i 1}(t), \xi_{j 1}(t)$ - defines the place of the soldier on the battlefield and whether he has been spotted by the adversary,

$\eta_{i 2}(t), \xi_{j 2}(t)$ - defines the character of combat actions of the soldier (observation, firing),

$\eta_{i 3}(t), \xi_{j 3}(t)$ - defines combat capability of the soldier (injured, free from injury),

$\eta_{i 4}(t), \xi_{j 4}(t)$ - defines the amount of ammunition available for the soldier.

Functions $\eta_{i 1}(t), \eta_{i 2}(t), \eta_{i 3}(t)$ can have two

meanings -0 (has not spotted, is selecting a target, is not injured) and 1 (has spotted, is firing, is injured). The methodology for ascribing the appropriate meaning will be discussed below.

\subsection{Estimation of terrain features in planning the course of the battle}

Let us assume that a reconnaissance patrol has determined the approximate location of an enemy waiting in ambush and a hundred-man-strong company was issued an order to clear the way for the movement of the main effort. Let us assume that the assault starts with the enemy being at the distance of $\approx 600 \mathrm{~m}$. In offence, the company covers a strip about one kilometer long and while moving military personnel retain a distance of $d \approx 8 \div 12 \mathrm{~m}$ from each other. If the soldiers launch the attack $\Delta_{1} \approx 3-4 s \quad$ (denying the adversary time to aim) at a random moment of time $\Delta t_{2} \approx 14-16 \mathrm{~s}$, we will analyze the movement by changing time at the intervals of $\Delta t=\Delta t_{1}+\Delta t_{2} \approx 18-20 \mathrm{~s}$. Such movement can be described as relocation to another square (the sides of the squares are $\approx 10 \times 10 \mathrm{~m})$. We shall make the assumption that within this small distance visibility, relief, and other conditions change insignificantly.

We shall indicate the position of each soldier by writing down the indices of the appropriate square $x_{i j}$, i. e. the line $1 \leq i \leq 60$ and the column $1 \leq j \leq 100$ (if a hundred soldiers are advancing and the attack covers a frontal area of $10 \times 100=1000 \mathrm{~m}$, where the distance to the adversary is $10 \times 60=600 \mathrm{~m}$ ). We will define the position of the fortified enemy soldier by one index $y_{j}$ because the enemy soldiers are fortified and will not change their position during the battle (column index $j$ indicates the position of the soldier in the fortified zone).

The estimation of the terrain features can be completely carried out by using the information of GIS space data. Figure 1 represents $5 \times 5 \mathrm{~km}$ square of a certain terrain in Lithuania.

Thus, the first stage in estimating the features of the terrain is making up of a visibility matrix of the battlefield. To that end, the battlefield shown in figure 2 is analyzed.

The attack site is selected and visibility conditions are analyzed for each singled-out square of the battlefield (Fig 3). A visibility matrix is made up, i. e. the squares $(\approx$ $10 \times 10 \mathrm{~m}$.) seen by the soldier, positioned at a certain site in the area indicated in figure 3, are marked by symbol "1", those that are not seen by symbol "0" (Tab 1).

The visibility zone of the soldier positioned in the square marked by the letter " $X$ " (an element of the matrix $[1,37]$ is analyzed. The table corresponds to the twodimensional matrix $[29 \times 80]$ that presents data about visibility on a $290 \times 800 \mathrm{~m}$ terrain. A tool capable of generalizing the data and giving an overall view of the visibility zone of the defending soldiers is being created. Having analyzed the visibility matrices of the chosen defense sites, we will be able to make a more appropriate decision for both defense and offense. 


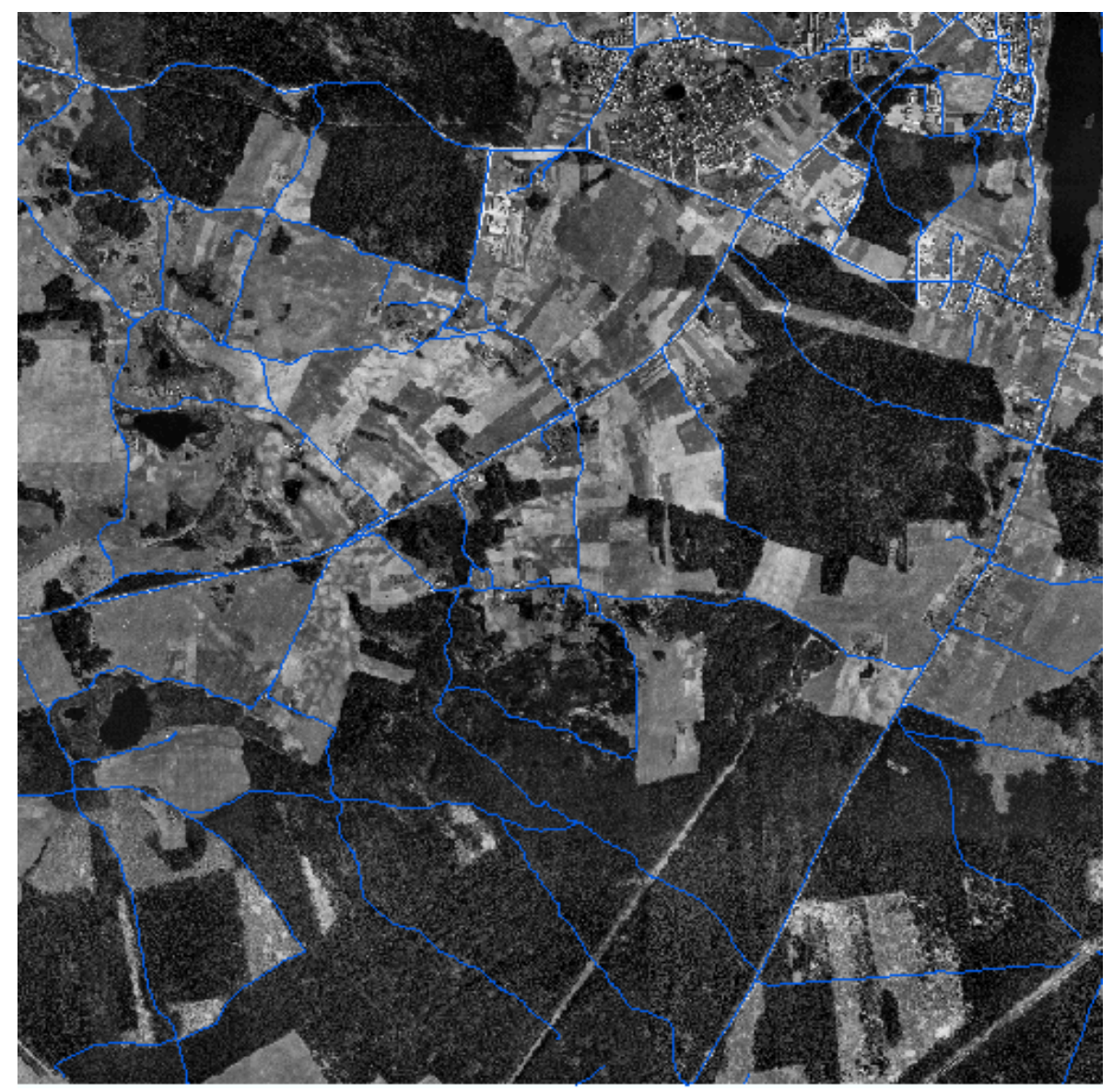

Fig 1. $5 \times 5 \mathrm{~km}$ square of Lithuanian terrain

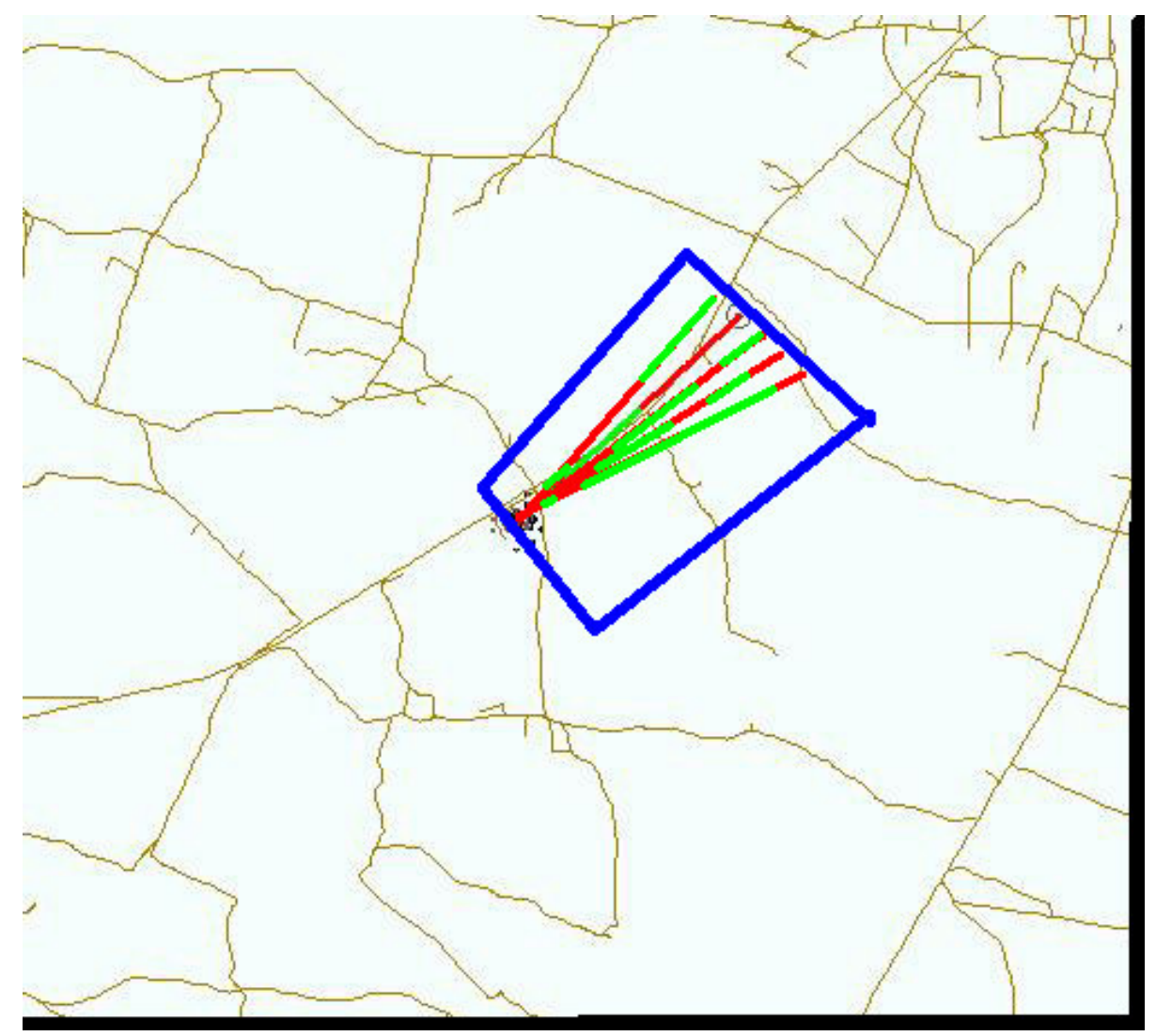

Fig 2. A selected attack site 


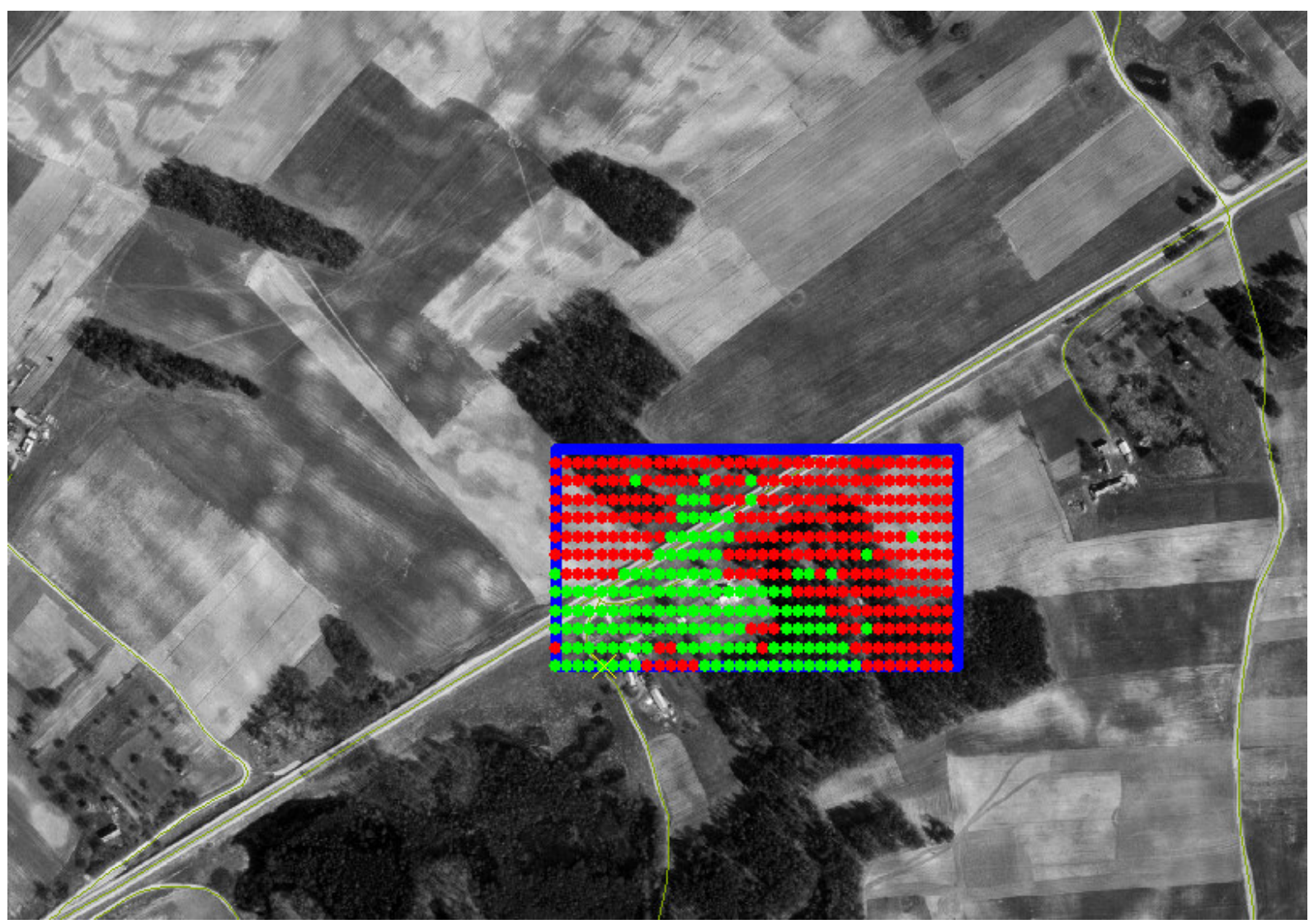

Fig 3. Battlefield squares $(\approx 10 \times 10 \mathrm{~m}$.) singled out for analysis

Table. Matrix of the visibility

00100000000000000000000000000000000000000000000000000000000000000000000000000000 00100000000000000000000000000000000000000000000000000000000000000000000000000000 00010000000001000000000000000000000000000000000000000000000000000000000000000000 00000100001010000000000000000000000000000000000010000000000000000000000000000000 00000000000000000000000000000000000000000000000000000000000011100000000000000000 00000000000001000000000000000000000000000000000000001100001000000000000000000000 00000000000000000000000000000000000000000000000010010000000000000000000000000000 00000000000000000000000010000000000000000000000000000000000000000000000000000000 00000000000000000000000010010001000000000000000000000000000000000000000000000000 00000001000000000000000001000000000000000000000000000000000000100000000000000000 00000000000010000010000000000000000000000000000000000000000000000000000000000000 00000000000000000010000000010000011001000000000000000000000000000000000000000000 00000000000000000000000000000100000000000000000000000000100000000000000000000000 00000000000000001111110000010010001000000000000000000000100101000000000000000001 00000000000000111111101000000000000000000000000000000000000001100000000000000000 00000000000001111111111100000000000000001000000000000000000000000010100000000000 00000000000000101111111111110000000000000000000000000000000000000000100000001000 00000001000000000011111111111111111111111100100000000000000000001000000000000000 00000000000000000011111111111111111111111111100000000000000000010000000000010000 00000000000000000001111111111111111111111111110000001010000000000000000000000000 00000000000000000001111111111111111111111111111100000000000000000000000000000000 00000000000000000011111111111111111111111111111111110010000000000000000000000000 00000010001111111111111111111111111111111111111111110000100000000000000000000000 01001010011111111111111111111111111111111111111111111000100000000000000000000000 00010010111111111111111111111111111111111111111111111000000000000000010000000000 00011000111111111111111111111111111111111111111111110000000000000000000000000000 00000001111111111100000011111111111111111111111111000000000000000000000000000000 00000011111111111000000000011111111111111111111110000000000000100000000000000000 $000011111110000110000000011111111111 \mathrm{X} 1111111111100000000000000010000000000000000$ 


\subsection{The estimation of the hit probability}

When firing a rifle, the probability of hitting the target depends on the distance to the target, type of weapon, accuracy of the soldier, meteorological conditions, and other factors. Deviations are distributed according to the two-dimensional normal distribution described by the formula $[7,5]$ :

$$
p_{g}(r)=\frac{1}{\pi \sigma_{x} \sigma_{y}} \int_{x_{1}}^{x_{2}} \int_{y_{1}}^{y_{2}} e^{\frac{\left(x-x_{m}\right)^{2}}{2 \sigma_{x}}} e^{\frac{\left(y-y_{m}\right)^{2}}{2 \sigma_{y}}} d x d y
$$

where the intervals $\left[x_{1}, x_{2}\right],\left[y_{1}, y_{2}\right]$ indicate the size of the target, $\left(x_{m}, y_{m}\right)$ are coordinates of the aiming point (distance from the weapon to the target), and $\sigma_{x}$ and $\sigma_{y}$ are average quadratic deviations. Weapon design features determine them. We will equate the interval $\left[x_{1}, x_{2}\right]$ along the direction of firing, i. e. along axis $\mathrm{x}$ direction with the range of a point blank shot when the bullet trajectory does not rise above the target throughout the entire flight [2]. The position of the enemy figure can be chosen at any place on the sight notch zone (soldiers are trained to move on the battlefield to possibly avoid an accurate enemy shot). In a concrete case, we divide the zone into only ten equal parts (because the result does not change if we increase the number of divisions), use formula (1) to work out the hit probability in each case, and afterwards compute the average of these probabilities [7]. The impact of the wind can also be included into these computations (data about how much wind of a certain speed diverts a bullet are usually known). For example, a medium-strength wind $(v=4 \mathrm{~m} / \mathrm{s})$, perpendicular to the firing plane, with the firing distance of $400 \mathrm{~m}$, diverts an AK74 bullet $0.5 \mathrm{~m}$ to the side [10]. If a bound (moving in bounds on the battlefield during the attack) lasts 2-4 seconds, and the adversary needs 5 seconds to take aim, the hit probability decreases. Its change can be estimated by employing the formula [1] that is widely used in the queuing theory:

$$
P_{i}(r)=1-e^{\frac{P(r) t_{i}}{t_{0}}}
$$

where $P(r)$ is mean hit probability when target distance is $r, t_{0}$ is the average time during which a soldier manages to take aim, $t_{i}$ stands for a random time interval (the time of the bound), for example 2-4 seconds. Having completed the aforementioned computations covering six points (every hundred meters), we generalize these computations by using the method of least squares. The dependence of the received hit probabilities on the duration of the bound ( $2 \mathrm{sec} ., 3 \mathrm{sec} .4 \mathrm{sec}$.) and distance is described by the formulae (3), (4), (5) when soldiers carry out defense in prepared positions and by formulae (6), (7), (8) when they launch an attack (graphic representation is given in figure 4$)$ :
$P_{1}(r)=-0.281133399310^{-8} r^{3}+0.380993274710^{-5} r^{2}$
$-0.001745603054 r+0,3039759662$

$P_{2}(r)=-0.390815500110^{-8} r^{3}+0.531083132110^{-5} r^{2}$
$-0.002447831409 r+0,4323335857$

$P_{3}(r)=-0.482871077610^{-8} r^{3}+0.658016818910^{-5} r^{2}$

$-0.003051648499 r+0,5468916946$

$P_{4}(r)=-0.50747694210^{-8} r^{3}+0.700239923910^{-5} r^{2}$

$-0.00331991022 r+0,6197141868$

$P_{5}(r)=-0.628594849610^{-8} r^{3}+0.874726856510^{-5} r^{2}$
$-0.004223751700 r+0.8211659650$

$P_{6}(r)=-0.69099627710^{-8} r^{3}+0.970310731110^{-5} r^{2}$

$-0.004779851704 r+0,9706942801$

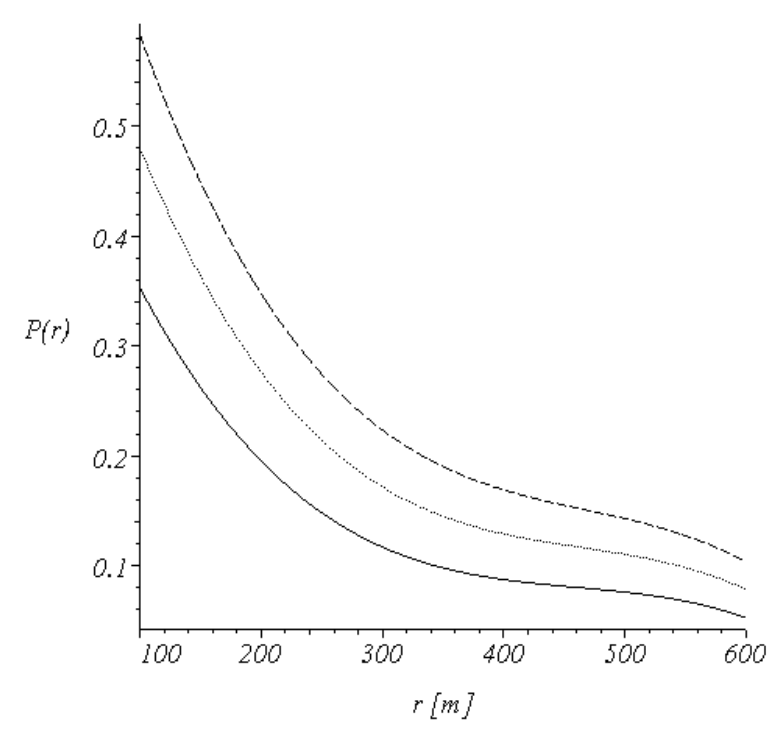

Fig 4. Dependence of hit probabilities on distance in offence if the bound time is: line -2 sec., dots -3 sec., strokes -4 sec.

Soldiers bearing automatic rifles choose enemy soldiers firing at them or those that are nearest to them and shoot after taking aim. Machine gunners fire partially taking aim or conduct area firing; grenade launcher and mortar fire usually destroys group targets or heavy weapons.

\section{Programs simulating the course of the battle}

We have analyzed a mathematical description of separate offensive elements: movement towards the enemy and observation, target acquisition, and firing. We have obtained analytical expressions, i. e. formulae (3), (4), (5), (6), (7), and (8) of the dependence of respective probabilities on the distance between the adversaries. We have mentioned that functions $\eta_{i 1}(t), \eta_{i 2}(t), \eta_{i 3}(t)$ can have two meanings - 0 (has not spotted, is selecting a 
target, is not injured) and - 1 (has spotted, is firing, is injured). Whether a concrete event has occurred is tested this way. For example, if hit probability in a concrete case, i. e. with the soldier being in a certain position, is equal to 0.4 , the random variable $r$, distributed according to the uniform law within the interval $(0,1)$, is generated and the condition

$$
r \leq P_{i}
$$

is checked. If the inequality (9) is satisfied, it is considered that the event has taken place and "the target has been hit". If it is not satisfied, the event has not taken place. The same model is used to check other events, for example "the enemy has been spotted". Afterwards the results are summed up, casualties and numbers of personnel further participating in the attack are counted. This is repeated until the battle ends, i. e. the time allotted for the battle ends, more than half of the personnel are killed, etc. Thus the results of one realization are obtained. Such computations are repeated 100-200 times and the average of the results is found (each realization is different because ever different random variables are generated) for each computed time moment (point). The number of realizations is increased until the obtained answer stops changing though the number of realizations is further increased with the indicated computation

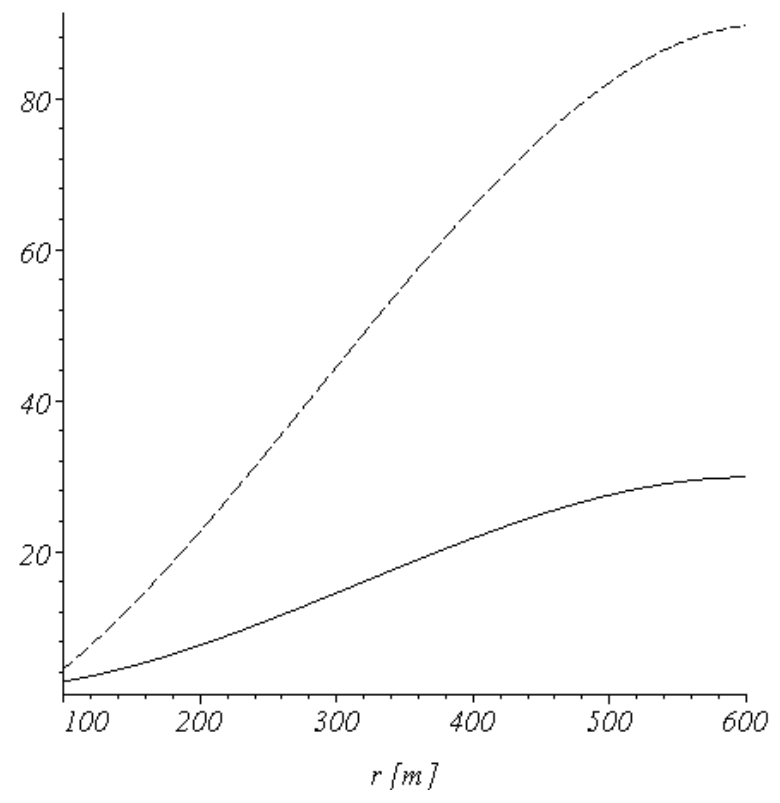

Fig 5. Change in the number of attacking (stroke line) and defending (line) soldiers during the attack. $r$-distance between the adversaries

\section{Conclusions}

Having summed up the results obtained, we can formulate these conclusions:

1. The developed programs make it possible to describe the combat actions of a concrete soldier and analyze the impact of numerous random factors on the course of the battle: the start of the attack, the duration of the bound and tactical elements (covering with fire from the flank, accuracy. A diagram of the program was provided in our work [7].

\section{Computation results and their discussion}

Using the information of GIS, it is possible to get a lot of useful information about the terrain where an attack or an ambush is to be conducted. They help determine sites from which the enemy will be clearly seen, to establish the more dangerous directions from which the enemy might approach the fortifications undetected, etc.

Using our programs it is possible to analyze different variants of enemy offence and defense and foresee more beneficial scenarios of the attack or defense. Figure 5 demonstrates a change in the number of attacking and defending military personnel when the assault is started with the distance between the fighting parties being $600 \mathrm{~m}$. We see that the attack should finish when the distance is $300 \mathrm{~m}$. because the attackers have lost half of their soldiers. Figure 6 presents the same assault described with reference to time. The attacking party would lose half of its soldiers within approximately 7-8 minutes. After completing program improvements, $i$. e. after introducing machine guns and heavy weapons into the battle, we could get a picture closer to reality.

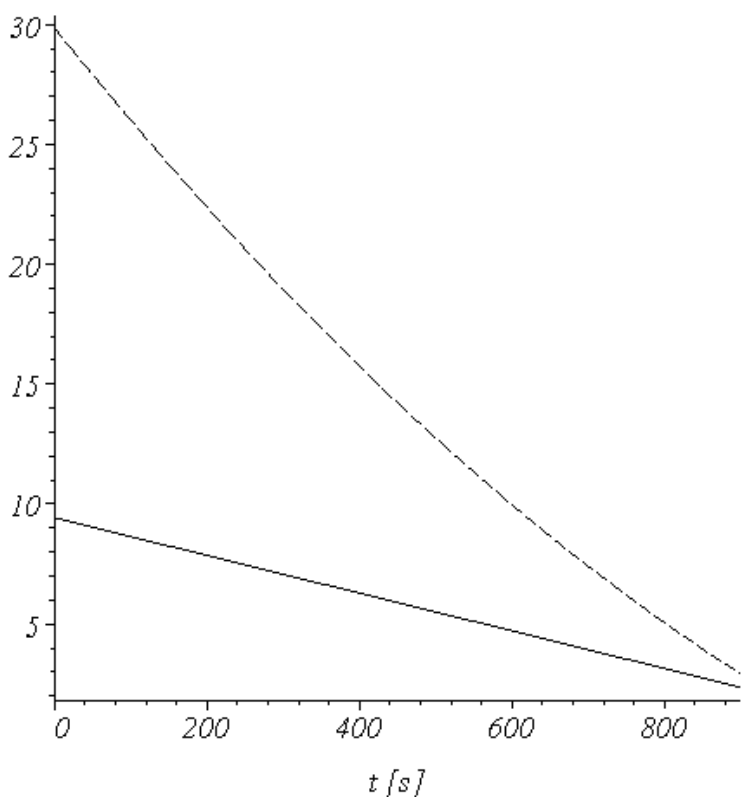

Fig 6. Change in the number of attacking (stroke line) and defending (line) soldiers during the attack. $t$ - time since the start of the attack

different types of soldiers' movement on the battlefield).

2. To estimate what influence makes the terrain, individual tactics and movement of military personnel to the course of the battle. Accurate and timely engineering estimation of the terrain creates preconditions for effective control of modern rapid military operations. Employment of digital maps and high-resolution digital satellite imagery of the terrain make it possible 
to carry out an effective analysis of the battlefield.

3. To compute the expenditure of military ammunition and estimate the quantity necessary to reach the desired result.

4. It is possible to analyze the impact of various weapons on the course of a battle.

It is possible to explore the impact of all these battle elements on the final result and use the programs in conducting classes for cadets in classrooms and in planning training at training areas.

\section{References}

1. Bryden K.M. Military-based virtual systems engineering // Proc. of the Winter Simulation Conference'2002. - 2002.

2. Franklin W.R., Vogt C. Multiple observers sitting on terrain with intervisibility or lo-res data // XXth Congress. International Society for Photogrammetry and Remote Sensing, Istanbul, 2004. - 2004.

3. Gilmer J.B., Sullivan Jr.F.J. The use of recursive simulation to support decisionmaking // Proc. of the Winter Simulation Conference'2003. - 2003.

4. Jančiauskas I., Venskus A. Balistika. - V.: Lietuvos karo akademija, 1999. - 102 p.

5. Misevičius G., Pincevičius A., Rakauskas R.J. ir kt. Aukštoji matematika. Intensyvių studijų kursas. V.:TEV, 1999. - 465 p.

6. Page E.H., Lunceford W.l H. Architectural principles for the U.S. Army's simulation and modeling for acquisition, requirements and training (SMART) initiative // Proc. of the Winter Simulation Conference'2001. - 2001.

7. Pincevičius A., Baušys R., Jankauskas P. Application of geographical information systems in modeling of military operations // AVIATION. - V.: Technika, 2005. - Vol IX, No 3. - P. 36-42.

8. Whelan M., Loftus J., Perme D. et al. Reducing training costs through integration of simulations, C4I systems and expert systems // Proc. of the Winter Simulation Conference'2002. - 2002.

9. Венцель Е.С. Исследование операций // Советское радио. - Москва, 1972. - 552 с.

10. Ткаченко П.Н. и др. Математические модели боевых действий // Ibid. 1969. - 240 c. 